\title{
Multiple Equilibria as a Possible Mechanism for Decadal Variability in the North Atlantic Ocean
}

\author{
ANDREAS BORN \\ Climate and Environmental Physics, Physics Institute, University of Bern, and Oeschger Centre for Climate \\ Change Research, Bern, Switzerland \\ JULIETTE MignOT \\ Sorbonne Universités (UPMC, Université Paris 06)-CNRS-IRD-MNHN, LOCEAN Laboratory, IPSL, Paris, \\ France, and Climate and Environmental Physics, Physics Institute, University of Bern, and Oeschger Centre \\ for Climate Change Research, Bern, Switzerland \\ THOMAS F. STOCKER \\ Climate and Environmental Physics, Physics Institute, University of Bern, and Oeschger Centre for Climate \\ Change Research, Bern, Switzerland
}

(Manuscript received 27 November 2014, in final form 24 August 2015)

\begin{abstract}
Decadal climate variability in the North Atlantic has received increased attention in recent years, because modeling results suggest predictability of heat content and circulation indices several years ahead. However, determining the applicability of these results in the real world is challenging because of an incomplete understanding of the underlying mechanisms. Here, the authors show that recent attempts to reconstruct the decadal variations in one of the dominant circulation systems of the region, the subpolar gyre (SPG), are not always consistent. A coherent picture is partly recovered by a simple conceptual model solely forced by reanalyzed surface air temperatures. This confirms that surface heat flux indeed plays a leading role for this type of variability, as has been suggested in previous studies. The results further suggest that large variations in the SPG correspond to the crossing of a bifurcation point that is predicted from idealized experiments and an analytical solution of the model used herein. Performance of this conceptual model is tested against a statistical stochastic model. Hysteresis and the existence of two stable modes of the SPG circulation shape its response to forcing by atmospheric temperatures. The identification of the essential dynamics and the reduction to a minimal model of SPG variability provide a quantifiable basis and a framework for future studies on decadal climate variability and predictability.
\end{abstract}

\section{Introduction}

A wealth of studies point to the Atlantic subpolar gyre (SPG) as a key component in North Atlantic decadal climate variability (e.g., Delworth et al. 1993; Lohmann et al. 2009a; Robson et al. 2012; Yeager and Danabasoglu 2014). Although a comprehensive description is not yet available, quasi-periodic (Yoshimori et al. 2010), potentially stochastically forced (Born and Mignot 2012) oscillations of the SPG promise a high potential to improve

Corresponding author address: Andreas Born, Physics Institute, University of Bern, Sidlerstrasse 5, 3012 Bern, Switzerland.

E-mail: born@climate.unibe.ch decadal climate predictions (Matei et al. 2012; Wouters et al. 2013; Kirtman et al. 2013). Idealized prediction experiments suggest a forecast potential of up to 20 years in the North Atlantic (Boer and Lambert 2008; Msadek et al. 2010; Branstator et al. 2012). Variations in the SPG are tightly coupled with changes in the deep overturning circulation and therewith modulate interhemispheric heat transport. Furthermore, the horizontal gyre dominates the meridional heat transport at subpolar latitudes (Rhein et al. 2011). It also determines the amount of heat advected into the Nordic seas and eventually into the Arctic Ocean (Holliday et al. 2008), with consequences for the sea ice cover (Lehner et al. 2013). Farther south, the SPG was found to influence the frequency of Atlantic 
hurricanes as well as their predictability with a lead time of several years (Dunstone et al. 2011).

In light of these and other far-reaching consequences, the abrupt weakening of the SPG in the mid-1990s has become a research topic of continued interest. Geostrophic velocities derived from satellite altimetry data show a distinct weakening of the gyre by $7-10 \mathrm{~Sv}$ ( $1 \mathrm{~Sv} \equiv$ $10^{6} \mathrm{~m}^{3} \mathrm{~s}^{-1}$ ) (Häkkinen and Rhines 2004), corresponding to up to one-quarter of its total volume transport of 3742 Sv (Bacon 1997; Read 2000; Fischer et al. 2004, 2010; $\mathrm{Xu}$ et al. 2013). Several case studies with decomposed surface forcing reproduced these changes with good fidelity, and it is now well accepted that they were caused by a transition to warmer winter air temperatures over the Labrador Sea around 1995 with a potential impact of a concurrent anomaly of warm water advected from the subtropical Atlantic (Böning et al. 2006; Lohmann et al. 2009b; Yeager et al. 2012; Robson et al. 2012; Msadek et al. 2014). This is in good agreement with reports of a concomitant reduction in Labrador Sea deep convection (Lazier et al. 2002).

However, process studies of the SPG rarely go beyond the decomposition of forcing factors in general circulation models (Eden and Willebrand 2001; Eden and Jung 2001), or the statistical or qualitative description of potential oscillation cycles (Delworth et al. 1993; Eden and Greatbatch 2003; Born and Mignot 2012; Escudier et al. 2013; Born et al. 2013). So far, only a handful of studies deduce the gyre's dynamics from first physical principles, including Straneo (2006b), Spall (2012), and Born and Stocker (2014), whereof the latter concludes that the SPG may have two stable modes of circulation manifested by a hysteresis. Consistent conclusions were reached in idealized experiments with a coarseresolution ocean general circulation model (Levermann and Born 2007).

The purpose of this study is to investigate variations in the SPG in 11 observed and reanalyzed datasets and to what degree they are represented in two simplified models. The four-box model by Born and Stocker (2014) is compared with a previously proposed stochastic autoregressive model (Eden and Greatbatch 2002; Mecking et al. 2014). We find that both models reproduce the time evolution of the SPG as estimated by comprehensive ocean data assimilation methods for the past several decades with good detail when forced by reanalysis surface air temperatures. The simplified yet explicit and physically consistent description of the SPG dynamics in the box model allows us to interpret abrupt transitions, such as the one in the mid-1990s, as a shift across the bifurcation point of the system into the monostable part of its parameter space. The box model also enables us to quantify the role of hysteretic memory. The bifurcation is the result of an advective-convective positive feedback mechanism. It has been long known that weaker Labrador Sea convection weakens the SPG as a consequence of a decrease in thermal wind (Marshall and Schott 1999). Nonlinearity in the response of the SPG, and thus its hysteretic behavior, is due to the fact that a weak SPG feeds back onto convection by transporting less salt into the region. It is this mutual amplification that causes the nonlinear response to atmospheric forcing. This conceptual framework is found to be relevant for the latest reconstructions of the SPG over the past decades.

The ocean reanalysis data, the stochastic model, and the box model of the SPG are presented in section 2 . Section 3 assesses how the two models compare with the reanalysis data. The importance of initial conditions on the simulation of the SPG is shown in section 4 . We discuss and summarize the results in section 5 .

\section{Methods}

\section{a. Reanalysis data and observations}

The strength of the SPG circulation is estimated from nine reanalysis products based on sparse observations assimilated by numerical models. This choice is made because representative long-term observations of the SPG are not available. The SPG index in these reanalysis datasets is defined as the average of the depthintegrated streamfunction in the region $45^{\circ}-64^{\circ} \mathrm{N}$, $60^{\circ} \mathrm{W}-35^{\circ} \mathrm{W}$, the same as for the atmospheric reanalysis driving the box model, multiplied by -1 to obtain positive values (Fig. 1). This region is relatively large, as is required to capture the relevant variability that is located in slightly different regions in the different underlying numerical models. For a similar reason, the alternative definition as the minimum of the (negative) streamfunction is not practical here, because it may be influenced by small recirculation centers that might be at different locations in different models, show different dynamics, and change location when two such localized phenomena compete. The more robust definition used here corresponds to the western part of the region used in a previous model intercomparison (Born et al. 2013), the region for which our box model is designed.

In addition to reanalyzed data, we use two SPG indices based on sea surface height data. The first is the first principal component of sea surface height derived from satellite altimetry (Häkkinen and Rhines 2004), extended through September 2014. A second dataset combines satellite data and interpolated tide gauge measurements to cover the period from 1950 through 2009 (Hamlington et al. 2011). Here, the SPG index is obtained by averaging the sea surface height between 


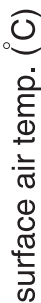

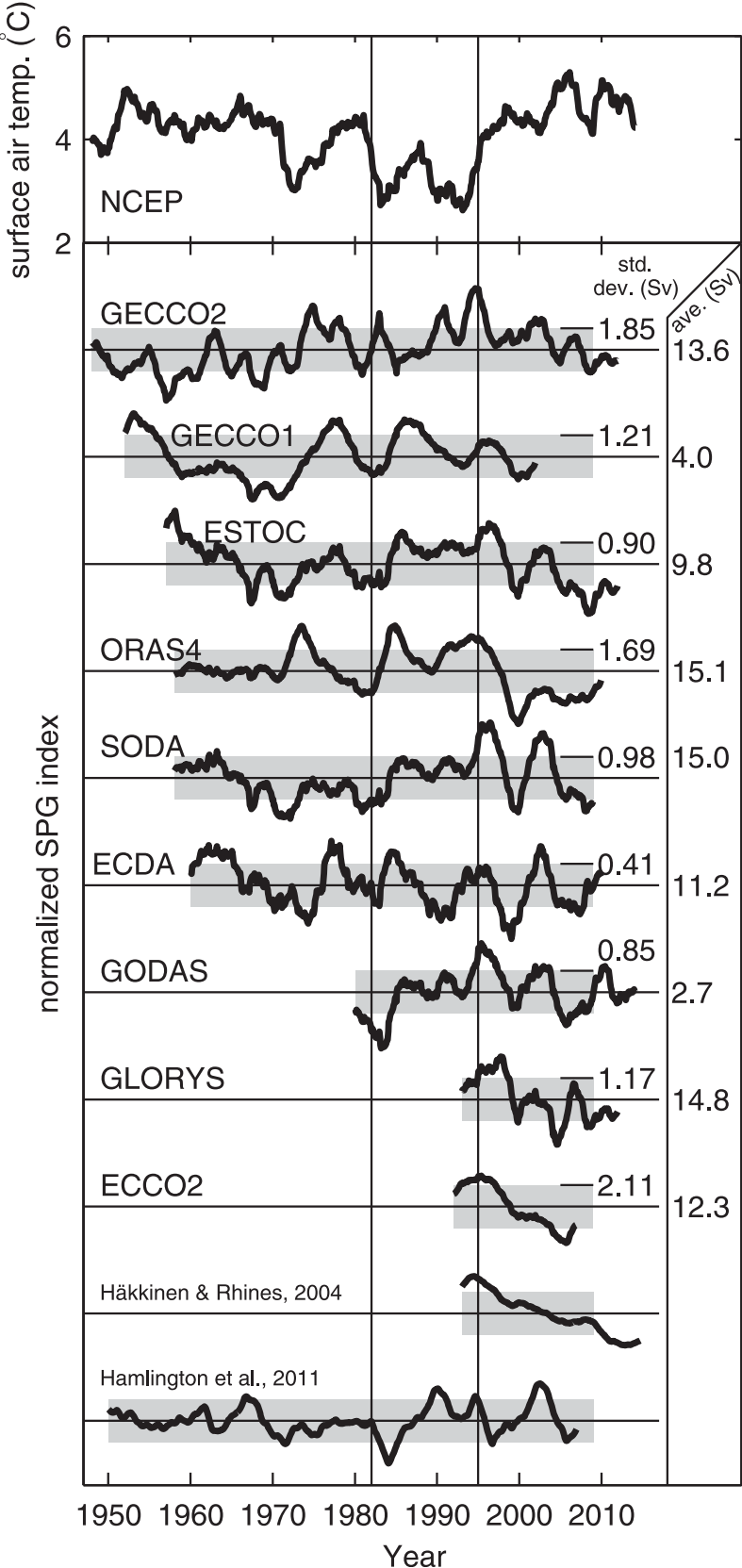

FIG. 1. Subpolar gyre index for a range of reanalysis products and two indices based on sea surface height, normalized to a standard deviation of one. (top) The NCEP air temperature used to force the box model. All curves have been deseasonalized and smoothed with a 2-yr running average. Average circulation strength and one standard deviation are shown on the right side where appropriate. Vertical lines mark the beginning of years 1982 and 1995 .

$45^{\circ}-60^{\circ} \mathrm{N}$ and $60^{\circ}-35^{\circ} \mathrm{W}$ and subtracting the global average sea level. The northern limit of the region does not extend to $64^{\circ} \mathrm{N}$ because of data availability. All 11 datasets have a homogeneous resolution of one month.

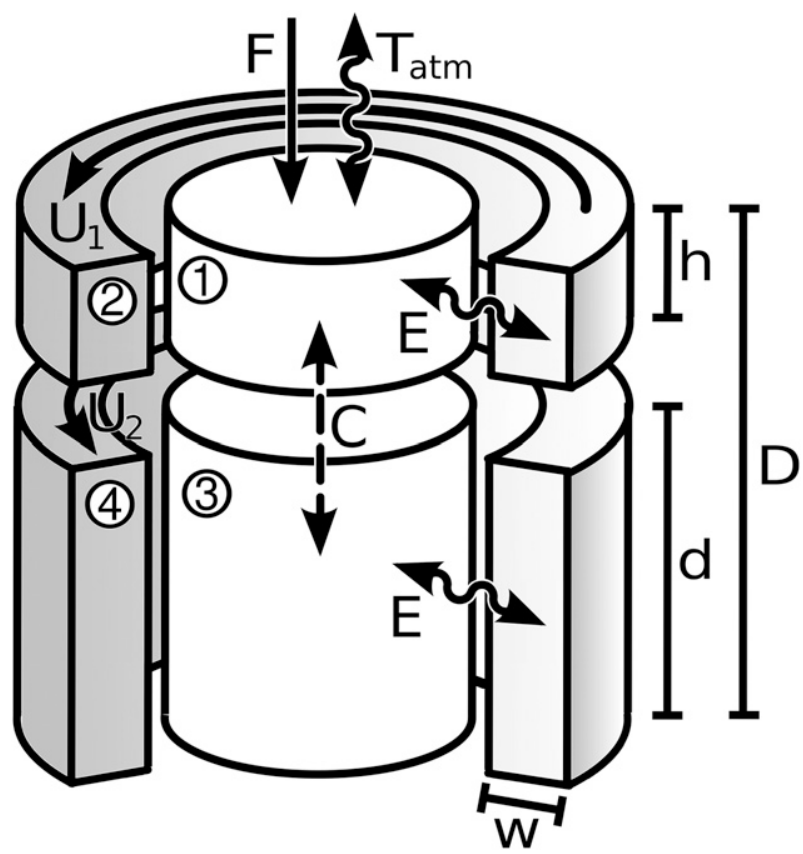

FIG. 2. Four-box model of the subpolar gyre. Volume transport is divided in upper $U_{1}$ and lower $U_{2}$ boundary current. External forcing is represented by a constant freshwater flux $F$ and relaxation to daily atmospheric temperatures $T_{\mathrm{atm}}$. Internal fluxes of heat and salt are represented by convection $\mathrm{C}$ in the vertical and lateral eddy mixing $\mathrm{E}$.

\section{b. Stochastic and physical models of the subpolar gyre}

Two simplified models are considered to simulate the decadal variations of the SPG as reconstructed by the different datasets presented above. The physical box model used in this paper was originally proposed by Born and Stocker (2014). It consists of four boxes: two cylindrical boxes representing a convective basin and two more for the boundary currents surrounding it (Fig. 2). The two upper boxes have a depth of $100 \mathrm{~m}$; the lower two reach the bottom of convective mixing, which is adjusted as detailed below. Although considerably simplified, this setup approximates more complex numerical experiments (Spall 2004; Iovino et al. 2008) and the WOCE Atlantic Repeat Line 7 (AR7) section across the Labrador Sea (Marshall and Schott 1999; Straneo 2006a; Yashayaev 2007). The total depth of the model is motivated by the depth of Labrador Sea Water in the boundary current (Straneo 2006b; Yashayaev 2007; Holliday et al. 2009). Temperatures $\left(T_{2}, T_{4}\right)$ and salinities $\left(S_{2}, S_{4}\right)$ of the outer boxes are fixed to represent the waters of the Irminger Current and Icelandic Slope Current, respectively, where the latter is a mixture of Iceland-Scotland Overflow Water and Labrador Sea Water recirculating in the basin (van Aken and de Boer 
1995). For the inner two boxes, these properties are simulated prognostically by the model:

$$
\begin{aligned}
& \partial_{t} T_{1}=2 r^{-1} c^{*} U_{1}\left(T_{2}-T_{1}\right)+\tau^{-1}\left(T_{\mathrm{atm}}-T_{1}\right), \\
& \partial_{t} S_{1}=2 r^{-1} c^{*} U_{1}\left(S_{2}-S_{1}\right)-F_{S}, \\
& \partial_{t} T_{3}=2 r^{-1} c^{*} U_{2}\left(T_{4}-T_{3}\right), \quad \text { and } \\
& \partial_{t} S_{3}=2 r^{-1} c^{*} U_{2}\left(S_{4}-S_{3}\right),
\end{aligned}
$$

where $T_{n}$ and $S_{n}$ are the temperature and salinity of box $n$ (see Fig. 2); $r$ is the radius of the central boxes; and $U_{1}$ and $U_{2}$ are the velocities of the upper and lower boundary currents, respectively. Lateral exchange between the upper and lower boundary currents $\left(U_{1}\right.$ and $U_{2}$ ) and the inner basin at their respective depth is parameterized as eddy mixing with the dimensionless efficiency coefficient $c^{*}$ (Visbeck et al. 1996; Spall and Chapman 1998). Surface forcing is applied only to the upper central box. It is represented here by a constant freshwater influx $F_{S}=1 \mathrm{~m} \mathrm{yr}^{-1}$ and monthly varying surface air temperatures $T_{\text {atm }}$ to which the temperature of the upper central basin relaxes on a time scale of $\tau=30$ days. Surface air temperatures are taken from the NCEP monthly atmospheric reanalysis data (Kalnay et al. 1996), averaged over the region $45^{\circ}-64^{\circ} \mathrm{N}, 60^{\circ}-$ $35^{\circ} \mathrm{W}$ between January 1948 and September 2014 and modified with a constant offset between $-2^{\circ}$ and $2^{\circ} \mathrm{C}$. The monthly NCEP forcing is interpolated linearly to the daily time step of the box model. This transient forcing is one major difference to the original version by Born and Stocker (2014). Data from ERA-40 (Uppala et al. 2005) averaged over the same region are very similar in the overlapping period. However, coverage of the NCEP reanalysis starts earlier and extends to the present and is thus preferred here.

The eddy interaction between the upper central basin and the upper boundary current is essential to the nonlinearity of the box model as described by the advectiveconvective feedback mechanism: A stronger boundary current sheds more eddies into the relatively fresh central basin, effectively increasing its salinity and density. This lowers the threshold for deep convection, resulting in a longer convective winter season and therefore a stronger heat loss of the entire water column to the atmosphere. As a consequence, the higher density of the central water column causes a stronger thermal wind and thus an enhanced boundary current, which again strengthens the salt flux to the center by eddies.

Note that, interestingly, in the absence of eddy mixing $\left(c^{*}=0\right)$, Eq. (1) represents an autoregressive process of order one (AR1) for the temperature of the upper layer with the stochastic white noise forcing $\tau^{-1} T_{\text {atm }}$
(Hasselmann 1976; Frankignoul and Hasselmann 1977). Equation (2) for salinity takes a similar form with infinite persistence $\left(\tau^{-1} S_{1}=0\right)$, which can be interpreted as an upper limit of the fact that sea surface salinity indeed has a longer persistence than sea surface temperature because of the lack of an air-sea feedback (e.g., Frankignoul and Kestenare 2002). Thus, the box model can be seen as a physically based extension of the commonly used AR1 process that is known to describe well the stochastic variability in sea surface temperatures. However, without the transport of freshwater by eddies, the surface freshwater flux accumulates in the central water column, which leads to an unrealistic and unrecoverable shutdown of convection.

Autoregressive models with stochastic forcing are frequently used to describe the time evolution of climate variables. In general, an autoregressive process of order $n(\mathrm{AR} n)$ takes the form

$$
X(t)=\sum_{h=1}^{n} \varphi_{h} X(t-h)+\varepsilon^{\prime},
$$

where the current value of the variable $X(t)$ is determined as the sum of the $n$ previous discrete time steps, weighted by $n$ autoregressive parameters $\varphi_{h}$ and white noise $\varepsilon^{\prime}$. AR1 processes with $\varphi_{1}>0$ act as a lowpass filter on $\varepsilon^{\prime}$ and have a spectral density similar to red noise. They are often used as a simple description of variability in sea surface temperatures (Frankignoul and Hasselmann 1977) and salinity (Mignot and Frankignoul 2003) for regions where lateral advection by strong ocean currents is negligible. Previous studies propose that time variations of the SPG circulation can be represented as an AR5 model with a time step of $1 \mathrm{yr}$ (Eden and Greatbatch 2002; Mecking et al. 2014).

\section{Results}

The absolute circulation strength and its standard deviation differ considerably between reanalysis datasets, although they are forced with (subsets of) similar observational datasets (Fig. 1). We speculate that differences are likely due to different assimilation methods and biases in the underlying general circulation models. However, most estimates of the average circulation fall in the range of $10-15 \mathrm{~Sv}$. Standard deviations are between 0.4 and $2.1 \mathrm{~Sv}$. Common features include a strong SPG during the 1970s, followed by a weaker phase and renewed strengthening in the early 1980s. A phase of relative strength continues until approximately 1995, after which most datasets show a strong weakening. Thus, the same major transitions are present in all datasets, albeit with large variations in their relative 
TABLE 1. Autoregressive parameters $\varphi_{h}$ determined by the covariance of the SPG index time series for each reanalysis and sea level observation dataset. The last column shows the resulting correlation coefficient between the original SPG time series and the AR5 model forced with surface air temperature (boldface values are above 95\% significance threshold) for the time after 1960 (except for GODAS, which starts in 1980).

\begin{tabular}{lcrrrrrl}
\hline \hline \multicolumn{1}{c}{ Dataset } & \multicolumn{1}{c}{$\varphi_{1}$} & \multicolumn{1}{c}{$\varphi_{2}$} & \multicolumn{1}{c}{$\varphi_{3}$} & \multicolumn{1}{c}{$\varphi_{4}$} & \multicolumn{1}{c}{$\varphi_{5}$} & Correlation coef $(95 \%, 99 \%)$ & Reference \\
\hline GECCO2 & 0.39 & -0.09 & 0.04 & 0.51 & -0.27 & $0.28(0.41,0.55)$ & Köhl (2015) \\
GECCO1 & 0.74 & 0.40 & -0.34 & -0.33 & 0.20 & $\mathbf{0 . 6 5}(0.46,0.61)$ & Köhl and Stammer (2008) \\
ESTOC 02b & 0.41 & 0.24 & -0.04 & -0.10 & 0.10 & $\mathbf{0 . 4 8}(0.41,0.55)$ & Masuda et al. (2010) \\
ORAS4 & 0.85 & -0.05 & -0.13 & 0.03 & -0.02 & $\mathbf{0 . 7 8}(0.42,0.56)$ & Balmaseda et al. (2013) \\
SODA 2.1.6 & 0.62 & 0.01 & -0.12 & -0.12 & 0.23 & $0.24(0.42,0.57)$ & Carton and Giese (2008) \\
ECDA & 0.25 & 0.10 & -0.07 & -0.37 & 0.07 & $0.04(0.42,0.56)$ & Zhang et al. (2007) \\
GODAS & 0.28 & -0.06 & -0.07 & -0.09 & -0.02 & $-0.06(0.51,0.68)$ & www.cpc.ncep.noaa.gov/ \\
products/GODAS/ & & & $-0.08(0.43,0.58)$ & Hamlington et al. (2011) \\
HL11 & 0.48 & -0.07 & -0.03 & -0.17 & 0.02 & &
\end{tabular}

amplitudes and the exact timing of their onset. Similar variations are found in the indices based on sea surface height. ECCO, phase II (ECCO2), and the Häkkinen and Rhines (2004) dataset in particular show remarkable agreement in their near-linear decrease after the early 1990s. However, the linear trend is interrupted by relatively strong phases around the years 2000 and 2010, in good agreement with the other datasets. The succession of maxima and minima is nevertheless in good qualitative agreement with independent direct estimates of the SPG transport (Curry and McCartney 2001; Sidorenko et al. 2008), as well as high-resolution hindcasts (Böning et al. 2006; Deshayes and Frankignoul 2008; Lohmann et al. 2009a).

\section{a. Simulation of reanalysis data with stochastic and physical models}

The autoregressive parameters of the AR5 model are calculated for all datasets, excluding the three shortest ones (Table 1). Only data after 1960 are taken into account, which are available from all remaining datasets except for GODAS, for which data start in 1980. Moreover, agreement for the 1950s is limited, and the extremely high values in the earliest part of the Estimated State of the Global Ocean for Climate Research (ESTOC), for example, appear to upset the parameter estimation procedure, resulting in significantly worse results. For the AR5 process to account for information of the previous $5 \mathrm{yr}$, and for consistency with previous studies (Eden and Greatbatch 2002; Mecking et al. 2014), the data are downsampled to a resolution of $1 \mathrm{yr}$.

The parameter estimation is based on the least squares regression of the covariance function of the SPG index to estimate the parameters from the reanalysis data, but other methods, such as Yule-Walker, yield undistinguishable results. We note that the autoregressive parameters of orders higher than one $\left(\varphi_{2-5}\right)$ are considerably smaller than $\varphi_{1}$ for the majority of the datasets. In these cases, the AR5 model has only a modest advantage over a much simpler AR1 stochastic model. Time series for the individually tuned stochastic models are then calculated by forcing the AR5 model with the normalized time series of annual-average surface air temperatures (Fig. 3). The quality of the fit is quantified by means of a cross correlation. Of the eight datasets, three are significantly correlated with their respective stochastic model: first version of GECCO (GECCO1), Ocean Reanalysis System 4 (ORAS4), and ESTOC. Interestingly, these three datasets have among the highest persistence of $\varphi_{1}$, which also results in notably smoother time series in the stochastic model.

Similarly to the stochastic model, the box model is fitted to the data with five free parameters. However, here the parameters are constrained by physically reasonable limits. They comprise the total vertical extent of the model $D[d+h$ in Born and Stocker (2014)], an offset applied to the surface air temperature of the reanalysis $\Delta T_{\mathrm{atm}}$, the salinity of the upper boundary current $S_{2}$, the barotropic volume transport $M_{\text {btp }}$, and the eddy mixing efficiency $c^{*}$ (Table 2). Permitted values for these quantities are $D=\{1100,1200, \ldots, 2100 \mathrm{~m}\}$, whereof the depth of the upper boxes $h$ remains unchanged at $100 \mathrm{~m} ; \Delta T_{\mathrm{atm}}=\left\{-2^{\circ},-1.5^{\circ}, \ldots, 2^{\circ} \mathrm{C}\right\} ; S_{2}=$ $\{34,34.1, \ldots, 36 \mathrm{psu}\} ; M_{\mathrm{btp}}=\{10,15, \ldots, 40 \mathrm{~Sv}\}$; and $c^{*}=\{0.015,0.03,0.045,0.06\}$, resulting in a total of 30492 unique combinations. All possible parameter combinations are then forced with the monthly time series of surface air temperatures, and cross-correlation coefficients are calculated for the time after 1960. Note that, in contrast to the stochastic model, the box model requires forcing at monthly resolution because the model explicitly simulates convective events that are sensitive to specific winter temperatures. The model versions that best correlate with each individual reanalysis dataset are shown in Fig. 4 and in Table 2. 

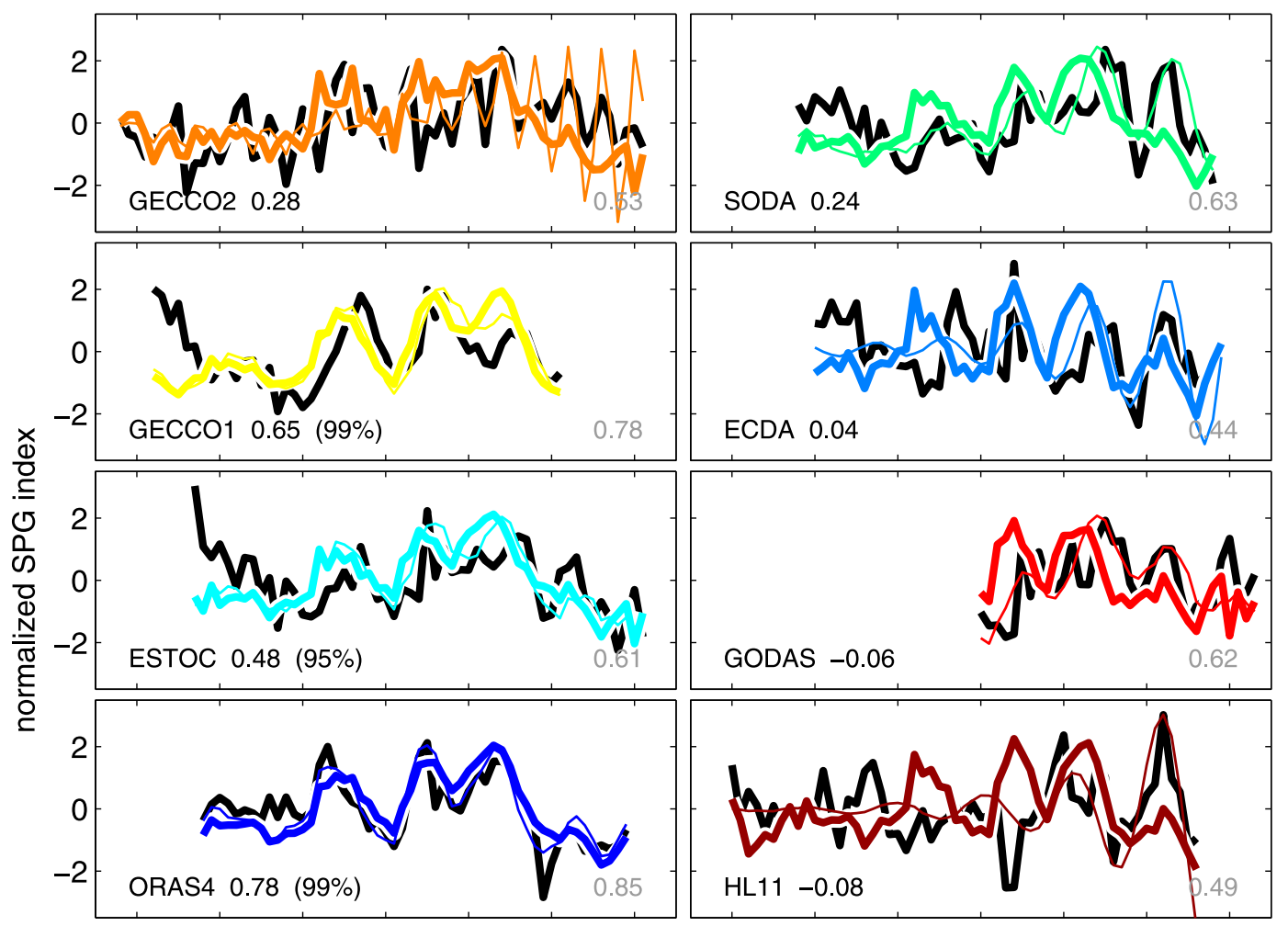

1950196019701980199020002010

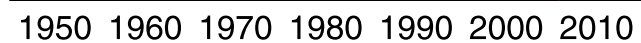

FIG. 3. Normalized time series of reanalyzed SPG indices (black), and individual fits of AR5 models (colors). Two stochastic models are shown for each dataset: one based on a parameter estimation from the covariance function of the original data (thick line) and the second determined as the parameter set that yields the highest cross correlation with its respective dataset out of a large ensemble of simulations (thin line). Correlation coefficients for the covariance method are on the bottom left of each panel, together with their significance estimate, where appropriate. The correlation coefficients of the AR5 models fitted with the ensemble method are shown in gray on the bottom right of each panel.

Although the physical box model provides monthly data, the correlation coefficients are calculated from resampled yearly data to ensure results comparable to the stochastic model. Six of the eight datasets yield significant correlations above the $95 \%$ threshold (Table 2).

Note that for the box model we use cross correlations to both select and quantify the quality of the agreement of an extensive ensemble with the reanalysis data, while the selection and the assessment of the stochastic model use different methods. To bridge this methodological gap, a second fit was calculated for the stochastic model by selecting the best correlation from a large ensemble of simulations the same way as for the box model. The five autoregressive parameters $\varphi_{h}$ were allowed to vary

TABLE 2. Best-fitting parameter set for each reanalysis and sea level observation dataset used for the box model. The fifth column shows the resulting correlation coefficient between the SPG index of each dataset and the corresponding box model version forced with surface air temperature (boldface values are above 95\% significance threshold) for the time after 1960 (except for GODAS, which starts in 1980).

\begin{tabular}{lcccccc}
\hline \hline \multicolumn{1}{c}{ Dataset } & $D(\mathrm{~m})$ & $\Delta T_{\mathrm{atm}}\left({ }^{\circ} \mathrm{C}\right)$ & $\mathrm{S} 2(\mathrm{psu})$ & $M_{\text {btp }}(\mathrm{Sv})$ & $c^{*}$ & Correlation coef $(95 \%, 99 \%)$ \\
\hline GECCO2 & 2100 & 1.5 & 34.7 & 35 & 0.015 & $\mathbf{0 . 5 2}(0.41,0.55)$ \\
GECCO1 & 2100 & -2.0 & 34.1 & 40 & 0.015 & $\mathbf{0 . 5 9}(0.46,0.61)$ \\
ESTOC 02b & 1100 & -1 & 34.4 & 15 & 0.015 & $\mathbf{0 . 6 3}(0.41,0.55)$ \\
ORAS4 & 1500 & 0.0 & 34.4 & 15 & 0.045 & $\mathbf{0 . 7 7}(0.42,0.56)$ \\
SODA 2.1.6 & 2100 & 0.5 & 34.6 & 10 & 0.045 & $\mathbf{0 . 5 5}(0.42,0.57)$ \\
ECDA & 1700 & 1.5 & 34.9 & 10 & 0.03 & $0.39(0.42,0.56)$ \\
GODAS & 1600 & -2.0 & 34.1 & 30 & 0.015 & $\mathbf{0 . 5 3}(0.51,0.67)$ \\
HL11 & 2000 & -1.0 & 34.3 & 10 & 0.045 & $0.42(0.43,0.58)$ \\
\hline
\end{tabular}



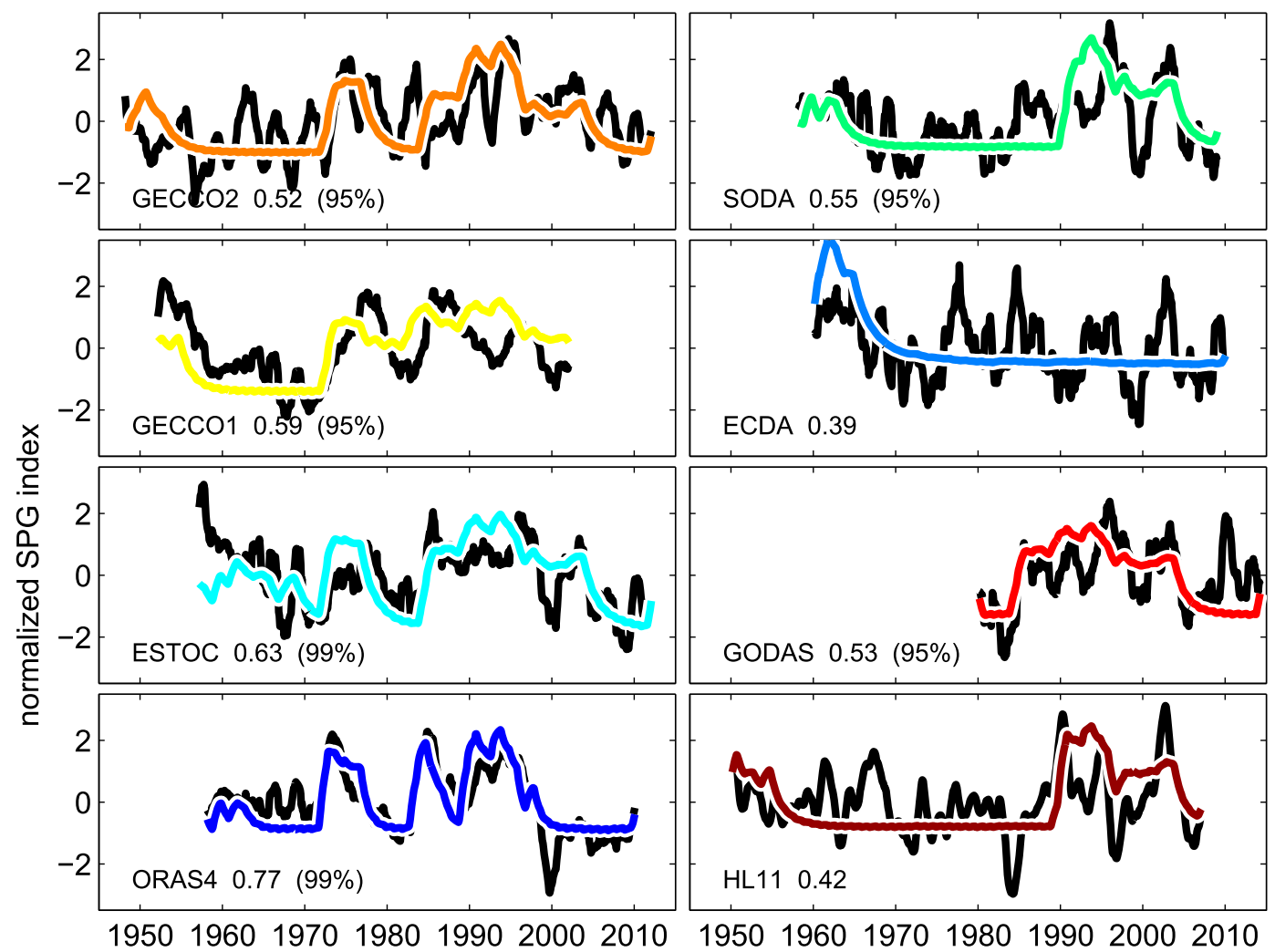

FIG. 4. As in Fig. 3, but the colored curves now represent the best fit for the box model. The monthly data of the box model and reanalysis datasets are smoothed with a 13-month running average filter. Correlation coefficients are calculated from yearly averages as for the stochastic model.

in the range $\{-1,-0.75, \ldots, 1\}$, for a total of 59049 unique combinations. Analogous to the box model, the best parameter set for each reanalysis dataset was selected based on the cross correlation of the annual average values (Fig. 3, thin lines). This method yields correlation coefficients (Fig. 3, bottom right in each panel) that are considerably higher than the best match calculated from the data covariance function above and, in almost all cases, better than the box model. However, four of the new stochastic model versions show an unstable oscillation with growing amplitude [second version of GECCO (GECCO2), SODA, Ensemble Coupled Data Assimilation (ECDA), and the Hamlington et al. (2011) dataset (HL11)]. Moreover, the autoregressive parameters selected in this way lose their statistical relationship with the reanalysis data and have no physical constraint. Since this approach has the same degrees of freedom but no constraints, a very good agreement with the reanalysis data is not surprising. For these reasons, we argue that these fits of the stochastic model do not advance our physical or statistical understanding of variations in the SPG circulation, and we will therefore not consider them further in the remainder of this work.
For the significantly correlated box model versions, large differences exist for $T_{\text {atm }}$ and $S_{2}$. The former might be due to differences in the location of deep convection in the models used to assimilate observations into the reanalysis data. Theoretically, a more southern location requires a more positive offset. However, additional offsets may result from sea ice and freshwater biases that are common in global circulation models, such as the ones used to produce reanalysis data. Since the cross correlation is performed on normalized time series, a match in absolute strength between box model and original reanalysis data is not expected.

All box model versions with significant correlations agree on a relatively strong phase of the SPG in the 1980s and 1990s (Fig. 5a). With the parameter set that best matches ORAS4, a strong decline is simulated after 1995, while all other parameter sets yield a partial weakening at the same time followed by a second one in the mid-2000s. Four of the six parameter sets simulate a strong SPG in the 1970s, and all simulations show a relatively strong circulation in the 1950 s, a finding that is ambiguous from the reanalysis datasets (Fig. 1). Note that the SPG circulation of the 1960s and 1970s was also 

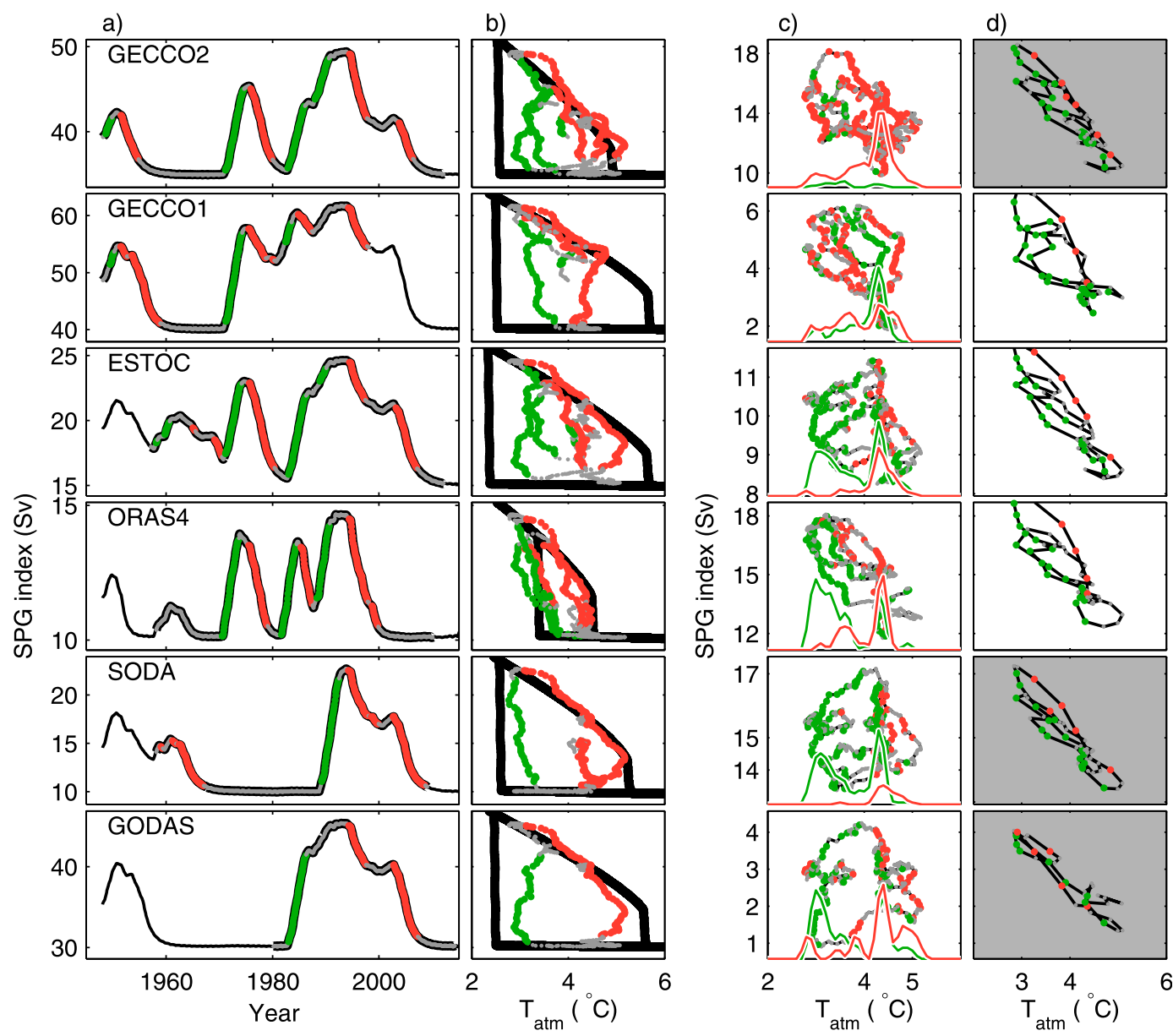

FIG. 5. SPG index as simulated by the box model (a) as a function of time and (b) as a function of air temperature. The thin line in (a) is the entire simulation; the thick line is the time interval that overlaps with the respective reanalysis data. Colored dots highlight periods of strong strengthening (green) and weakening (red), defined as the upper and lower third of the range of the time derivative of the SPG index. Idealized quasi-equilibrium forcing is shown as a black curve in (b). (c) SPG index vs $T_{\text {atm }}$ for reanalysis data. Histograms show the density of dots of the same color as a function of temperature. (d) As in (b), but for the AR5 model. Simulations with a cross correlation below the $95 \%$ significance threshold (Fig. 3) have gray background. All transient curves are smoothed with a 3-yr running average filter.

influenced by the Great Salinity Anomaly (Dickson et al. 1988; Belkin et al. 1998) (e.g., potential variations in $S_{2}$ that are not included in the box model). The impact of variations in $S_{2}$ will be discussed below. We believe that, given the simplicity of the mechanisms represented in the box model, these common features help to give a robust picture.

\section{b. Hysteresis in the SPG time series}

The box model is known to have two stable modes of circulation for the SPG, caused by an advectiveconvective positive feedback mechanism where convection and (eddy-) transport of salt into the convective center mutually reinforce each other (Born and Stocker 2014). Transitions between these stable modes follow a hysteresis if convection is perturbed with freshwater, as shown in Born and Stocker (2014). We will now illustrate that a hysteresis also occurs for variations in surface air temperature for all parameter sets that significantly correlate with the reanalysis data (Table 2).

The box model is run with slowly varying air temperatures. A realistic annual cycle is preserved by varying monthly temperature values between their respective minima and maxima in the entire NCEP record. This method is more realistic than using the climatological average annual cycle plus an increasing offset, because variations in the annual average temperature of the transient simulation are mostly due to changes in winter. Thus, the simulation starts with the lowest temperatures for each month, which increase linearly to the 
maximum monthly values. This increase takes 500 years to remain in continuous (quasi-) equilibrium. After reaching the maximum, an equally slow decrease starts until the surface temperatures arrive at their minimum again. As with variations in freshwater flux, the strength of the SPG describes a hysteresis with respect to variations in surface air temperature (Fig. 5b). For annual average temperatures below $2.5^{\circ} \mathrm{C}$, only the upper stable mode of circulation exists for all parameter combinations. In this case, deep convection is active in every winter season, and the baroclinic circulation component is active over the entire depth of the model domain. The strength of the simulated SPG decreases with higher temperatures in an approximately linear way but remains on the upper branch of the hysteresis until the bifurcation point is met between $4.7^{\circ}$ and $5.7^{\circ} \mathrm{C}$, depending on the parameter set. There, the SPG abruptly weakens to the lower circulation mode which is the only stable solution for higher temperatures. Here, convection is inhibited by too-warm surface waters, remaining density gradients between the lower center and the lower boundary current quickly erode, and the baroclinic circulation anomaly disappears. Lowering the surface air temperature again, the SPG remains on the lower branch of the hysteresis throughout the bistable range until it moves up to the strong mode again in the monostable range at low temperatures.

The transient simulations of the box model, forced with monthly NCEP surface air temperatures (the same simulations as in Fig. 4) are reproduced in Fig. 5a. As a function of surface air temperature, they approximately follow the hysteresis (Fig. 5b, colored dots). Deviations are due to the large changes in surface air temperature (Fig. 1) occurring faster than the 3-yr relaxation time of the box model (Born and Stocker 2014). Large weakenings of the simulated SPG are consistent with the system moving across the bifurcation point, where the upper branch of the hysteresis disappears at high temperatures. Similarly, abrupt strengthening of the SPG occurs for low temperatures where the lower branch becomes unstable. A marked temperature difference exists between ascending and descending trajectories. Thus, the hysteresis enforces a primarily clockwise trajectory in the $T_{\mathrm{atm}}-\mathrm{SPG}$ index space. Anticlockwise movement is possible as long as the SPG does not cross the unidirectional thresholds from one flow regime into the other. This is best observed in the series of modest variations on the upper branch of the hysteresis around 1990 in GECCO1, GECCO2, and ESTOC (Figs. 5a,b). As long as the SPG stays in the strong regime, corresponding to the upper branch of the hysteresis, the SPG responds approximately linearly to variations in surface air temperature. The hysteresis also reveals that flat parts in the transient curves correspond to prolonged periods in the weak regime. These are periods without deep convection and therefore have limited sensitivity to variations in surface air temperature.

Alongside the trajectory of the box model in $T_{\mathrm{atm}^{-}}$ SPG index space, the trajectories of the ocean reanalysis time series are plotted against the NCEP surface air temperature record (Fig. 5c). These data are smoothed with the same 3-yr running average filter as the box model data but are otherwise unchanged. As expected from the time series in Figs. 3 and 4, the trajectories of the reanalyzed data are much more variable. The density of weakening occurrences is highest for surface air temperatures above $4^{\circ} \mathrm{C}$ in all datasets, while temperatures below $4^{\circ} \mathrm{C}$ predominantly lead to an increase, except for GECCO1 and GECCO2 (Fig. 5c, thin lines). This corresponds to the clockwise trajectory found in the box model with a separation between the ascending and descending branches. However, the reanalysis data show a second maximum in the density of strengthening occurrences for relatively high temperatures. Since the second maximum in strengthening occurrences coincides with the maximum density in weakening in all datasets, we speculate that it could also be the result of variations within the linear regime of the upper branch of the hysteresis. This is the anticlockwise movement also identified in the box model above, when the SPG does not cross the bifurcation point and therefore does not have to reach the transition point to become stronger again. However, it appears more likely that the more frequent strengthenings at high temperatures point to the importance of processes that are neglected in the box model, such as variations in wind stress or salinity. Warm temperatures over the Labrador Sea often correspond to the positive phase of the North Atlantic Oscillation, which is also related to changes in the wind field that could drive a strengthening of the SPG (e.g., Häkkinen et al. 2011; Moffa-Sánchez et al. 2014).

The results of the stochastic AR5 model are shown in Fig. 5d. Here, the time series of the stochastic model have been rescaled to match the average and the standard deviation of the reanalysis products. The background color of the three AR5 simulations, which significantly represent the variations in the respective datasets, is white; nonsignificant simulations are shown in gray. In contrast to the box model, the stochastic model generally reacts more linearly to variations in $T_{\text {atm }}$ (Fig. 5d). The three significantly correlated stochastic models for GECCO1, ESTOC, and ORAS4 also show an open figure and a clear separation between the ascending and descending branches of the $T_{\text {atm }}-\mathrm{SPG}$ index curves. This is the result of the relatively high 


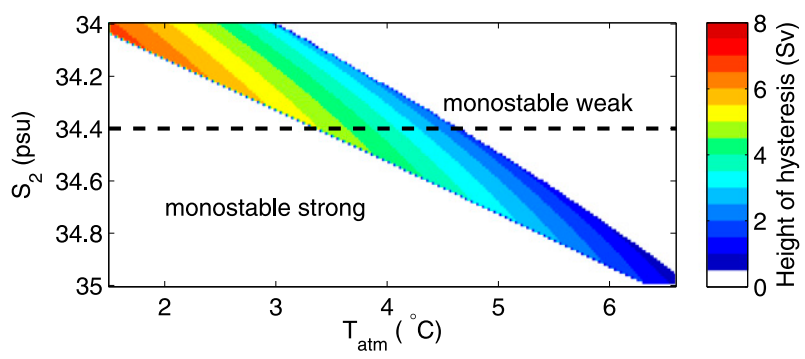

FIG. 6. Height of the hysteresis loop as a function of annual average temperature $T_{\text {atm }}$ and salinity of the upper boundary current $S_{2}$. The height of the hysteresis (vertical axis in Fig. 5b) decreases with higher annual average temperatures and higher salinities. The same is true for the width of the hysteresis, defined as the range of the bistable regime on the $T_{\text {atm }}$ axis. For high $T_{\text {atm }}$ and low $S_{2}$, the SPG is in its monostable weak regime. The weak branch disappears for low $T_{\text {atm }}$ and high $S_{2}$. The hysteresis presented for ORAS4 in Fig. 5 is a horizontal section at $S_{2}=34.4$ psu here (dotted line).

values of the autoregressive parameters (Table 1), indicative of some form of memory. A hysteresis is not a solution of the stochastic model [Eq. (5)]. The agreement between the stochastic models and the other reanalysis datasets could thus arguably be improved by higher autoregressive parameters. However, this is inconsistent with the parameter estimation based on the available data, possibly as a result of the brief observational time series. On the contrary, a physical explanation for the memory is provided by the box model: the hysteresis based on the advective-convective feedback mechanism.

Our simulations with the box model neglect variations in surface freshwater flux and surface salinity changes, mainly because high-quality continuous salinity data are not available for the past. We therefore restrict our analysis to the qualitative mechanisms. The height of the hysteresis and therefore the region of potential bistability for variations in both $T_{\text {atm }}$ and $S_{2}$ are shown in Fig. 6 for the set of parameters that best matches ORAS4. As before, $T_{\mathrm{atm}}$ is varied slowly with a constant $S_{2}$, but here this step is repeated for various values of $S_{2}$. This illustrates that a freshening, such as during the Great Salinity Anomaly, cannot directly explain a stronger SPG during the 1970s, as speculated above. Although lower salinities make the hysteresis loop wider and taller, they also shift it toward lower temperatures, further removing a potential transition to the strong circulation regime from the temperature range found in the NCEP surface air temperature record. However, the additional forcing component and thus additional degrees of freedom in the optimization exercise could help to improve the reproduction of the reanalysis datasets by the box model.

\section{Role of initial conditions}

\section{a. Box model response to post-1982 and post-1995 surface air temperatures}

We now concentrate on the hysteretic system of the box model and the possible consequences for decadal predictability of the SPG intensity. A hysteretic system does not only respond to the applied forcing but also depends on the history of the forcing. In other words, the hysteresis provides memory. Identifying such memory in the climate system is of highest interest in the context of decadal climate predictions. For brevity, we focus on the parameter set that best resembles the ORAS4 SPG index. The other parameter sets are qualitatively similar. Following the approach of Lohmann et al. (2009a), we apply the atmospheric forcing starting in July 1995 and 1982 to different starting years in the box model (Fig. 7). Splitting annual cycles in summer is paramount to avoid large discontinuities in the forcing, which is most variable in winter.

As expected, the series of mild winters starting in 1995 favors a weakening of the SPG (Figs. 7a,b). As in the ocean general circulation model of Lohmann et al. (2009a), early-to-mid-1990s initial conditions cause a pronounced drop in the SPG circulation strength, while starting years like 1980, the late 1990s, and 2005 are more robust to the warmer air temperatures. This response is readily understood with the hysteresis of the box model. In 1980 and during the second half of the 1990s, the SPG already is at or near the lower branch of the hysteresis (Figs. 4 and 5). Further atmospheric warming does not cause further weakening of the SPG, because previous warm winters already stopped deep convection, and the buoyancy-driven component of the SPG disappears. Consistent with this finding, the sharpest decrease is not found with the initial conditions of 1995, but rather between 1990 and 1994, because the SPG was stronger in these years. The qualitatively different response to the post-1995 forcing for starting years 1995 and 2005 is robust in all box model versions for the first 1.5 years (Fig. 7d).

The relatively low surface air temperatures after 1982 result in a strengthening of the SPG (Fig. 7c). Here again, the different starting years fall into two qualitatively different categories, where initial conditions with the SPG on the lower branch of the hysteresis show a vigorous strengthening (1982, 2000, and 2005) while starting years with an already strong SPG have a weaker response. As for the forcing starting in July 1995, the starting years 1995 and 2005 fall into these two different categories, a result that is consistent with the corresponding analysis in Lohmann et al. (2009a, their Fig. 2). We thus corroborate their conclusion that the weakening after 1995 was not an unconditional response to the 


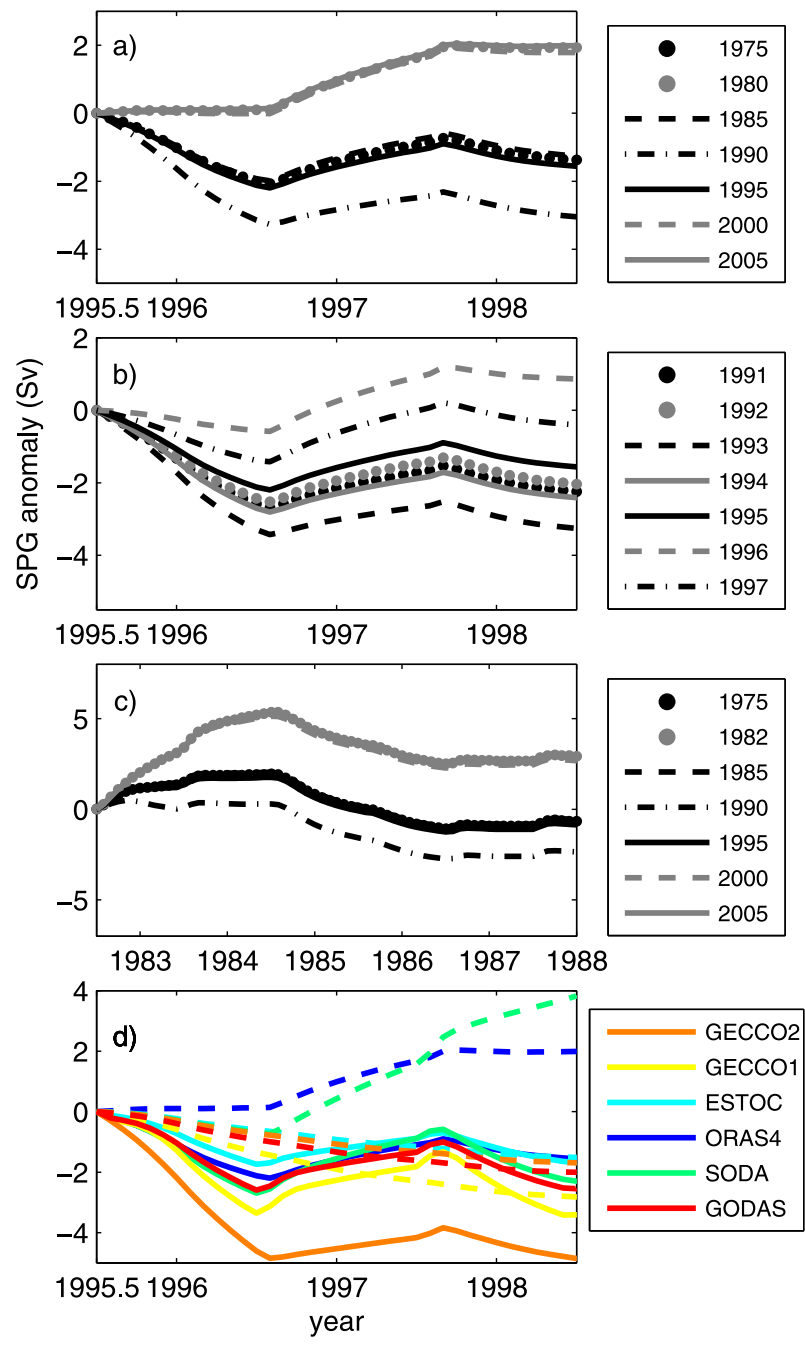

FIG. 7. SPG index as simulated by the box model with transient atmospheric forcing for different initial conditions. Atmospheric forcing starts in (a),(b),(d) July 1995 and (c) July 1982. The ORAS4 parameter set is used in (a)-(c). All significantly correlated parameter sets in (d) forced with surface air temperatures starting in July 1995 for initial conditions of June 1995 (solid) and June 2005 (dashed), equivalent to (a).

atmospheric conditions but actually a result of the strong SPG circulation in preceding years. The box model and its hysteresis provide a simple yet physically consistent explanation for this earlier finding.

\section{b. Tentative prediction of the SPG strength}

The apparently large influence of the initial conditions on the time evolution of the SPG index suggests a potential for predictions based on the known present state. Thus, a series of experiments was run in the box model with initial conditions of June 2014 and variable atmospheric boundary conditions thereafter. One experiment was started with forcing taken from each year
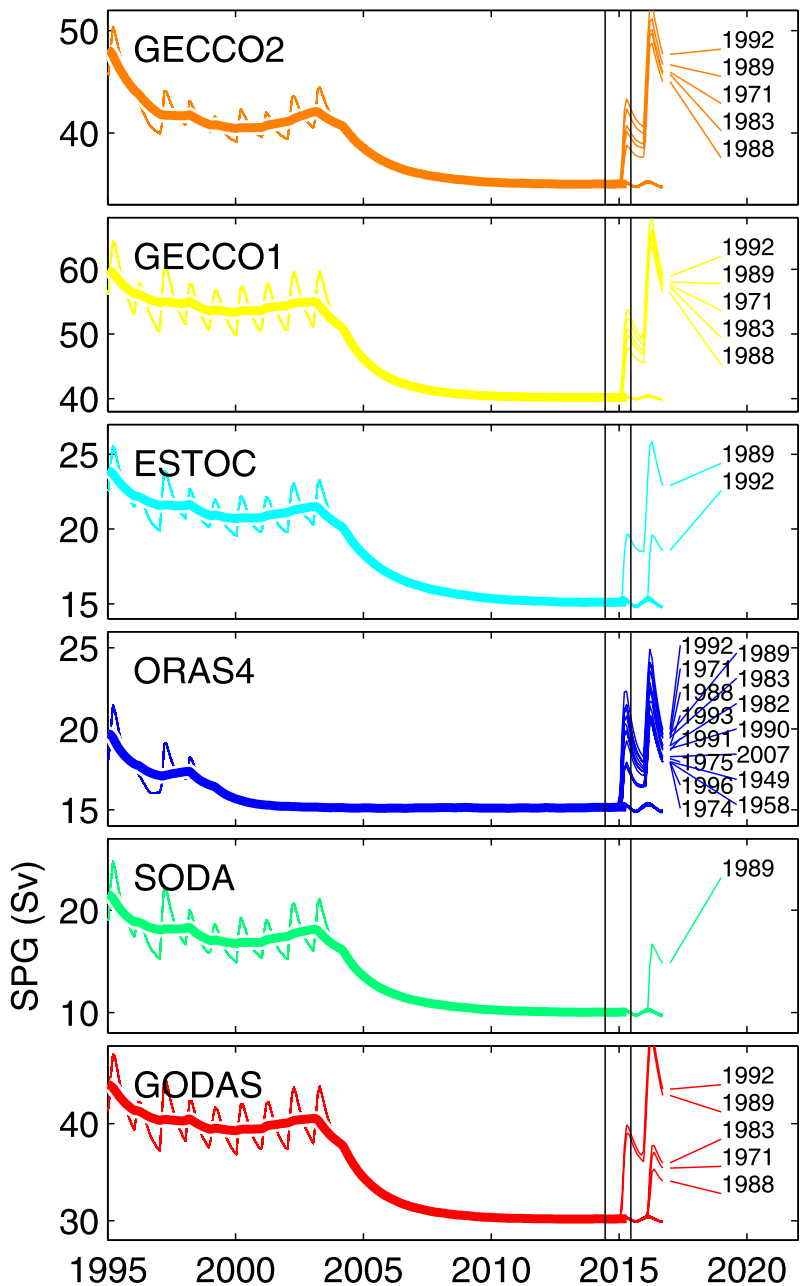

FIG. 8. Simulated SPG index forced with known surface air temperatures until June 2014 and fixed annual cycles of all available years thereafter. Thin colored lines show monthly data; thick lines show the 2-yr running average until June 2014. Vertical black lines highlight June 2014 and June 2015. Simulations with a strengthening in the forecast are labeled with their forcing year. All other forcing years are included in the overlapping curves below.

between 1948 and 2013, starting in July and following the annual cycle through June of the following year. After that, the same annual cycle is repeated once more. As an example, simulations labeled as 1992 in Fig. 8 have the following forcing sequence: July 1948-June 2014, July 1992-June 1993, and again July 1992-June 1993. The set of 66 realizations of forcing taken from the past is assumed to provide a reasonable range of possible future scenarios.

The results confirm that, after the long period of weak SPG circulation, the system is below the bifurcation point for all parameter sets. This excludes the possibility of a linear response to the temperatures in the winter of 
2014/15 and suggests either an abrupt recovery or no change at all. The responses of the different model versions are diverse. All model versions except SODA agree that a strengthening of the SPG circulation is possible in the first winter after the initialization. The SODA parameter set only achieves a strengthening in the second consecutive winter with 1989 temperature forcing. For the ORAS4 parameter set, 15 different forcing years lead to a strengthening of the SPG in the first winter after its initialization. This is because of its relatively narrow hysteresis (Fig. 5b) so that the bifurcation point is crossed relatively easily. Note that the winter of 1982/83 leads to a strengthening in only a few cases, although the sequence following July 1982 was shown to trigger a strong response (Fig. 7c). This is a consequence of separating the forcing years in summer and repeating the same annual cycle twice because it can lead to anomalously warm annual average temperatures if the summer at the beginning of the July-June window is delayed or if the following summer comes early. In the case of 1982, this counteracts the anomalously cold winter temperatures.

Disagreement between model versions regarding the stability of the present initial conditions complicates a precise prediction. This partly reflects differences between the reanalysis datasets toward which the box model version is optimized. In summary, the influence of the initial conditions seems to be limited, as one cold winter can be enough to overcome the hysteretic memory. However, most parameter sets suggest that the present SPG is firmly within its weak regime and that only winter temperatures comparable to the most severe of the past 66 years can change this situation.

\section{Discussion and summary}

In this study, we find that a simplified box model of the subpolar gyre, forced exclusively with reanalyzed surface air temperatures, produces time series that significantly correlate with the gyre strength as estimated in ocean reanalysis datasets and from variations in dynamic sea level. The reanalyses are based on comprehensive ocean general circulation models, forced with a full set of atmospheric forcing components, and assimilated to observed fields of ocean temperature and salinity to combine spatially and temporally sparse data into a complete four-dimensional dataset. The reconstructed time series of SPG circulation strength in these datasets show considerable disagreement over the past 60 years, emphasizing that the dynamics of the SPG and their representation in models are still insufficiently understood. The box model potentially offers an opportunity to improve on this situation, because it is limited to a small and well-defined set of physical mechanisms. Despite its simplicity, it yields results comparable to and better than a stochastic model that has the same number of degrees of freedom but is unconstrained by physics.

Our approach corroborates earlier findings that airsea heat flux is the dominant driver of SPG variations on decadal time scales (Böning et al. 2006; Lohmann et al. 2009b) but adds a considerably improved clarity to this concept because of the simplicity of the box model based on first physical principles. In this framework, variations of the SPG are readily identified as the system moving around a hysteresis loop. The existence of this hysteresis is predicted from idealized simulations and indeed from the analytical solution of the box model (Born and Stocker 2014). It is the result of a positive feedback mechanism involving Labrador Sea deep convection and the transport of saline water by the SPG. While it has been long known that enhanced deep convection strengthens the SPG through thermal wind (e.g., Marshall and Schott 1999), the feeding back of a strong SPG on the strength of convection by enhanced salt transport and its impact on dynamics have not been widely acknowledged. The results presented here suggest that both components are important to shape variability in the region. Only their combination can explain the relationship between surface air temperature and SPG strength of different reanalysis data products, which was found to be more complex than the expected delayed response from thermal wind alone (Fig. 5). An important role for this advective-convective positive feedback was also concluded from the statistical analysis of unforced variability in 19 coupled climate models (Born et al. 2013) and from idealized simulations in a coarse-resolution model (Mengel et al. 2012).

The SPG index of the reanalysis datasets is defined here as the average of the barotropic streamfunction over a relatively large region, motivated by the aim to capture the relevant variability that is located in slightly different regions in the different underlying numerical models. Thus, the SPG index probably includes not only the dynamics for which the box model is designed but also peripheral areas, which complicates the comparison of absolute values. Therefore, the optimization exercise uses normalized time series and focuses on the reproduction of relative variations instead.

The magnitudes of variations agree. Peak-to-peak variations in the reanalyses, between $\pm 2 \sigma$, have typical values of between 1.6 and $8.4 \mathrm{~Sv}$ (Fig. 1), values similar to those in the box model (not shown). In the center of the hysteresis loop between the two transition points, the upper and lower branches of the box model are separated by approximately one-third to one-quarter of 
the total transport (Fig. 5). Such relatively large variations are consistent with transport estimates from satellite altimetry (7-10 Sv; Häkkinen and Rhines 2004). Curry and McCartney (2001) quantify a $24 \%-33 \%$ change between 1970 and 1995, decadal in character, from ocean density observations, although this might include a contribution from the subtropical gyre.

Predictions of decadal ocean and climate variability are widely known to benefit from the initialization of the ocean (Kirtman et al. 2013), albeit the physical mechanisms are not always clear. For the SPG, one of the key components of decadal climate variability, the box model clarifies how the initial state depends on the position of the SPG on the hysteresis loop. Thus, after the sustained period of weak SPG circulation through June 2014, the box model predicts either a strong recovery if the following winter is cold enough to force a transition into the strong circulation regime or a negligible change in circulation otherwise. Given its initialization below the bifurcation point on the weak branch of the hysteresis for all plausible model parameter sets, a mild recovery of the SPG seems less likely. However, precise predictions can only be made with knowledge about future surface air temperatures, which somewhat undermines the effectiveness of initialization. Furthermore, uncertainty remains regarding the width of the hysteresis and its location on the $T_{\text {atm }}$ scale and, therefore, the resilience of the SPG to short-term transient changes in the air temperature forcing. Some model versions simulate a transition to the strong regime in the second winter after initialization because the forcing is not strong enough to erode the memory in the first winter. In this regard, the theoretical understanding of the box model highlights a potential limit for predictions that might also apply to comprehensive decadal prediction systems. Note, however, that longer time scales associated with advective processes or Rossby waves in the North Atlantic can significantly improve the initialization under certain circumstances but are not taken into account here (Lohmann et al. 2009b; Yeager et al. 2012; Robson et al. 2012; Sévellec and Fedorov 2013).

The Labrador Sea is one of the best-studied and most dynamically complex regions of the World Ocean. The large-scale scope of the box model consciously neglects this high complexity of small-scale currents at various depth levels in the region. The representation of surface forcing, the impact of sea ice, and other influences are kept to a minimum. While this radical simplification is necessary to obtain a minimal model of SPG variability, it potentially influences the results presented here. As an example, one shortcoming of our model is its fixed depth of convection, whereas mixing in the real ocean takes place over variable depths depending on the intensity of surface heat loss. Theoretically, a spectrum of convection depths would lead to a range of possible strong circulation modes (Born and Stocker 2014, their Fig. 10), potentially blurring the concept of two distinct modes of circulation. However, observations show that depths of $1500 \mathrm{~m}$ are reached even during periods of weak convective activity (Yashayaev 2007) so that the assumption of a continuous spectrum is likely exaggerated.

As mentioned above, the transport of salt by the SPG and its impact on deep convection are critical for the dynamics of the simplified model. Thus, the SPG strength reacts sensitively to the salinity of the upper boundary current and also follows a hysteresis (Born and Stocker 2014, their Fig. 4). The combined effect of surface air temperature and boundary current salinity changes is potentially important for the evolution of the SPG (Fig. 6). However, this effect is not considered in the analysis above because of the poor availability of continuous salinity observations. Observational and modeling studies often assign a secondary role to variations in sea surface salinity with regard to their impact on deep convection in the Labrador Sea (Curry and McCartney 2001; Böning et al. 2006). The presence of saline waters acts to decrease the convective threshold that nevertheless needs to be overcome primarily by cold winter temperatures. As a result of their dominance, cold winter surface air temperatures sometimes cause a convective event in spite of unfavorable freshwater conditions (Våge et al. 2009). From our perspective, a secondary role of variations in salinity is consistent with the relatively good fit of the time series from the model that was forced exclusively with variable surface air temperatures. On longer time scales, relevant for paleoclimatic events, changes in surface salinity have been shown to dominate modulations of the SPG (Thornalley et al. 2009; Born et al. 2010; Born and Levermann 2010; Born et al. 2011; Montoya et al. 2011; Irvali et al. 2012).

In summary, the simplified model of the SPG captures the essence of decadal circulation anomalies as simulated by much more sophisticated general circulation models remarkably well. The fingerprint of a hysteresis predicted by the box model can be found in reanalysis data. We believe that the condensed form of this concept, because of the mathematical and conceptual simplicity of the underlying box model, provides a robust framework for future investigations into the dynamics of the North Atlantic. Feasible modifications can include the effects of remote salt advection and sea ice or the interaction with the Atlantic meridional overturning circulation. Enabling such a gradual exploration of potentially important mechanisms, the box model bridges the gap between stochastic descriptions of variability that offer too little information on the underlying 
physics of ocean variability, if any at all, and comprehensive ocean general circulation models that often are overwhelmingly complex.

Acknowledgments. Compilation and public availability of the GECCO2, GECCO1, ESTOC, ORAS4, SODA, ECDA, GODAS, GLORYS, ECCO2, NCEP, and Hamlington reanalysis datasets are gratefully acknowledged. Data are made available by the University of Hamburg (http://icdc.zmaw.de/projekte/easy-init/ easy-init-ocean.html) and the Colorado Center for Astrodynamics Research (CCAR 2013). An updated version of the Häkkinen and Rhines (2004) SPG index was kindly provided by Dr. Sirpa Häkkinen (National Aeronautics and Space Administration Goddard Space Flight Center). A. B. received financial support from the European Commission under the Marie Curie Intra-European Fellowship ECLIPS (PIEF-GA-2011300544). J. M. received financial support from the EU project SPECS funded by the European Commission's Seventh Framework Research Programme under Grant Agreement 308378. T. F. S. received support from the Swiss National Science Foundation. This work was significantly improved by the comments of three anonymous reviewers.

\section{REFERENCES}

Bacon, S., 1997: Circulation and fluxes in the North Atlantic between Greenland and Ireland. J. Phys. Oceanogr., 27, 1420-1435, doi:10.1175/1520-0485(1997)027<1420:CAFITN>2.0.CO;2.

Balmaseda, M. A., K. Mogensen, and A. T. Weaver, 2013: Evaluation of the ECMWF ocean reanalysis system ORAS4. Quart. J. Roy. Meteor. Soc., 139, 1132-1161, doi:10.1002/qj.2063.

Belkin, I. M., S. Levitus, J. Antonov, and S. A. Malmberg, 1998: "Great Salinity Anomalies" in the North Atlantic. Prog. Oceanogr., 41, 1-68, doi:10.1016/S0079-6611(98)00015-9.

Boer, G. J., and S. J. Lambert, 2008: Multi-model decadal potential predictability of precipitation and temperature. Geophys. Res. Lett., 35, L05706, doi:10.1029/2008GL033234.

Böning, C., M. Scheinert, J. Dengg, A. Biastoch, and A. Funk, 2006: Decadal variability of subpolar gyre transport and its reverberation in the North Atlantic overturning. Geophys. Res. Lett., 33, L21S01, doi:10.1029/2006GL026906.

Born, A., and A. Levermann, 2010: The 8.2 ka event: Abrupt transition of the subpolar gyre toward a modern North Atlantic circulation. Geochem. Geophys. Geosyst., 11, Q06011, doi:10.1029/2009GC003024.

— Atlantic subpolar gyre: A stochastically forced oscillator. Climate Dyn., 39, 461-474, doi:10.1007/s00382-011-1180-4.

— subpolar gyre. J. Phys. Oceanogr., 44, 246-264, doi:10.1175/ JPO-D-13-073.1.

_ K. H. Nisancioglu, and P. Braconnot, 2010: Sea ice induced changes in ocean circulation during the Eemian. Climate Dyn., 35, 1361-1371, doi:10.1007/s00382-009-0709-2.
,-- , and B. Risebrobakken, 2011: Late Eemian warming in the Nordic seas as seen in proxy data and climate models. Paleoceanography, 26, PA2207, doi:10.1029/2010PA002027.

— T. F. Stocker, C. C. Raible, and A. Levermann, 2013: Is the Atlantic subpolar gyre bistable in comprehensive coupled climate models? Climate Dyn., 40, 2993-3007, doi:10.1007/ s00382-012-1525-7.

Branstator, G., H. Teng, G. A. Meehl, M. Kimoto, J. R. Knight, M. Latif, and A. Rosati, 2012: Systematic estimates of initialvalue decadal predictability for six AOGCMs. J. Climate, 25, 1827-1846, doi:10.1175/JCLI-D-11-00227.1.

Carton, J., and B. Giese, 2008: A reanalysis of ocean climate using Simple Ocean Data Assimilation (SODA). Mon. Wea. Rev., 136, 2999-3017, doi:10.1175/2007MWR1978.1.

CCAR, 2013: Reconstructed Sea Level, version 1. CCAR, University of Colorado, Boulder, accessed 11 March 2015, doi:10.5067/RECSL-000V1.

Curry, R. G., and M. S. McCartney, 2001: Ocean gyre circulation changes associated with the North Atlantic Oscillation. J. Phys. Oceanogr., 31, 3374-3400, doi:10.1175/ 1520-0485(2001)031<3374:OGCCAW>2.0.CO;2.

Delworth, T. L., S. Manabe, and R. J. Stouffer, 1993: Interdecadal variations of the thermohaline circulation in a coupled oceanatmosphere model. J. Climate, 6, 1993-2011, doi:10.1175/ 1520-0442(1993)006<1993:IVOTTC > 2.0.CO;2.

Deshayes, J., and C. Frankignoul, 2008: Simulated variability of the circulation in the North Atlantic from 1953 to 2003. J. Climate, 21, 4919-4933, doi:10.1175/2008JCLI1882.1.

Dickson, R. R., J. Meincke, S.-A. Malmberg, and A. J. Lee, 1988: The "great salinity anomaly" in the northern North Atlantic 1968-1982. Prog. Oceanogr., 20, 103-151, doi:10.1016/ 0079-6611(88)90049-3.

Dunstone, N. J., D. M. Smith, and R. Eade, 2011: Multi-year predictability of the tropical Atlantic atmosphere driven by the high latitude North Atlantic Ocean. Geophys. Res. Lett., 38, L14701, doi:10.1029/2011GL047949.

Eden, C., and T. Jung, 2001: North Atlantic interdecadal variability: Oceanic response to the North Atlantic Oscillation (1865-1997). J. Climate, 14, 676-691, doi:10.1175/1520-0442(2001)014<0676: NAIVOR $>2.0 . \mathrm{CO} ; 2$.

— and J. Willebrand, 2001: Mechanism of interannual to decadal variability of the North Atlantic circulation. J. Climate, 14, 2266-2280, doi:10.1175/1520-0442(2001)014<2266: MOITDV $>2.0 . \mathrm{CO} ; 2$.

_ , and R. J. Greatbatch, 2002: Prospects for decadal prediction of the North Atlantic Oscillation (NAO). Geophys. Res. Lett., 29, 104-1-104-4, doi:10.1029/2001GL014069.

— Atlantic climate system. J. Climate, 16, 4043-4060, doi:10.1175/ 1520-0442(2003)016<4043:ADDOIT>2.0.CO;2.

Escudier, R., J. Mignot, and D. Swingedouw, 2013: A 20-year coupled ocean-sea ice-atmosphere variability mode in the North Atlantic in an AOGCM. Climate Dyn., 40, 619-636, doi:10.1007/s00382-012-1402-4.

Fischer, J., F. A. Schott, and M. Dengler, 2004: Boundary circulation at the exit of the Labrador Sea. J. Phys. Oceanogr., 34, 1548-1570, doi:10.1175/1520-0485(2004)034<1548: BCATEO $>2.0 . \mathrm{CO} ; 2$.

- M. Visbeck, R. Zantopp, and N. Nunes, 2010: Interannual to decadal variability of outflow from the Labrador Sea. Geophys. Res. Lett., 37, L24610, doi:10.1029/2010GL045321.

Frankignoul, C., and K. Hasselmann, 1977: Stochastic climate models, Part II: Application to sea-surface temperature 
anomalies and thermocline variability. Tellus, 29A, 289-305, doi:10.1111/j.2153-3490.1977.tb00740.x.

— , and E. Kestenare, 2002: The surface heat flux feedback. Part I: Estimates from observations in the Atlantic and the North $\mathrm{Pa}$ cific. Climate Dyn., 19, 633-648, doi:10.1007/s00382-002-0252-x.

Häkkinen, S., and P. B. Rhines, 2004: Decline of subpolar North Atlantic circulation during the 1990s. Science, 304, 555-559, doi:10.1126/science.1094917.

—,- , and D. L. Worthen, 2011: Atmospheric blocking and Atlantic multidecadal ocean variability. Science, 334, 655-659, doi:10.1126/science.1205683.

Hamlington, B. D., R. R. Leben, R. S. Nerem, W. Han, and K.-Y. Kim, 2011: Reconstructing sea level using cyclostationary empirical orthogonal functions. J. Geophys. Res., 116, C12015, doi:10.1029/2011JC007529.

Hasselmann, K., 1976: Stochastic climate models. Part I. Theory. Tellus, 28A, 473-485, doi:10.1111/j.2153-3490.1976.tb00696.x.

Holliday, N. P., and Coauthors, 2008: Reversal of the 1960s to 1990s freshening trend in the northeast North Atlantic and Nordic seas. Geophys. Res. Lett., 35, L03614, doi:10.1029/2007GL032675.

_, S. Bacon, J. Allen, and E. L. McDonagh, 2009: Circulation and transport in the western boundary currents at Cape Farewell, Greenland. J. Phys. Oceanogr., 39, 1854-1870, doi:10.1175/2009JPO4160.1.

Iovino, D., F. Straneo, and M. Spall, 2008: The effect of a sill on dense water formation in a marginal sea. J. Mar. Res., 66, 325345, doi:10.1357/002224008786176016.

Irvali, N., and Coauthors, 2012: Rapid switches in subpolar North Atlantic hydrography and climate during the Last Interglacial (MIS 5e). Paleoceanography, 27, PA2207, doi:10.1029/ 2011PA002244.

Kalnay, E., and Coauthors, 1996: The NCEP/NCAR 40-year reanalysis project. Bull. Amer. Meteor. Soc., 77, 437-471, doi:10.1175/1520-0477(1996)077<0437:TNYRP>2.0.CO;2.

Kirtman, B., and Coauthors, 2013: Near-term climate change: Projections and predictability. Climate Change 2013: The Physical Science Basis, T. F. Stocker et al., Eds., Cambridge University Press, 953-1028. [Available online at https://www. ipcc.ch/pdf/assessment-report/ar5/wg1/WG1AR5_Chapter11_ FINAL.pdf.]

Köhl, A., 2015: Evaluation of the GECCO2 ocean synthesis: Transports of volume, heat and freshwater in the Atlantic. Quart. J. Roy. Meteor. Soc., 141, 166-181, doi:10.1002/qj.2347.

— , and D. Stammer, 2008: Variability of the meridional overturning in the North Atlantic from the 50 years GECCO state estimation. J. Phys. Oceanogr., 38, 1913-1930, doi:10.1175/ 2008JPO3775.1.

Lazier, J., R. Hendry, A. Clarke, I. Yashayaev, and P. Rhines, 2002: Convection and restratification in the Labrador Sea, 1990-2000. Deep-Sea Res. I, 49, 1819-1835, doi:10.1016/ S0967-0637(02)00064-X.

Lehner, F., A. Born, C. C. Raible, and T. F. Stocker, 2013: Amplified inception of European Little Ice Age by sea ice-oceanatmosphere feedbacks. J. Climate, 26, 7586-7602, doi:10.1175/ JCLI-D-12-00690.1.

Levermann, A., and A. Born, 2007: Bistability of the Atlantic subpolar gyre in a coarse-resolution climate model. Geophys. Res. Lett., 34, L24605, doi:10.1029/2007GL031732.

Lohmann, K., H. Drange, and M. Bentsen, 2009a: A possible mechanism for the strong weakening of the North Atlantic subpolar gyre in the mid-1990s. Geophys. Res. Lett., 36, L15602, doi:10.1029/2009GL039166.
,-- , and $-2009 \mathrm{~b}$ : Response of the North Atlantic subpolar gyre to persistent North Atlantic oscillation like forcing. Climate Dyn., 32, 273-285, doi:10.1007/s00382-008-0467-6.

Marshall, J., and F. Schott, 1999: Open-ocean convection: Observations, theory, and models. Rev. Geophys., 37, 1-64, doi:10.1029/98RG02739.

Masuda, S., and Coauthors, 2010: Simulated rapid warming of abyssal North Pacific waters. Science, 329, 319-322, doi:10.1126/ science.1188703.

Matei, D., H. Pohlmann, J. Jungclaus, W. Müller, H. Haak, and J. Marotzke, 2012: Two tales of initializing decadal climate prediction experiments with the ECHAM5/MPI-OM model. J. Climate, 25, 8502-8523, doi:10.1175/JCLI-D-11-00633.1.

Mecking, J. V., N. S. Keenlyside, and R. J. Greatbatch, 2014: Stochastically-forced multidecadal variability in the North Atlantic: A model study. Climate Dyn., 43, 271-288, doi:10.1007/ s00382-013-1930-6.

Mengel, M., A. Levermann, C. Schleussner, and A. Born, 2012: Enhanced Atlantic subpolar gyre variability through baroclinic threshold in a coarse resolution model. Earth Syst. Dyn., 3, 189-197, doi:10.5194/esd-3-189-2012.

Mignot, J., and C. Frankignoul, 2003: On the interannual variability of surface salinity in the Atlantic. Climate Dyn., 20, 555-565, doi:10.1007/s00382-002-0294-0.

Moffa-Sánchez, P., A. Born, I. R. Hall, D. J. R. Thornalley, and S. Barker, 2014: Solar forcing of North Atlantic surface temperature and salinity over the past millennium. Nat. Geosci., 7, 275-278, doi:10.1038/ngeo2094.

Montoya, M., A. Born, and A. Levermann, 2011: Reversed North Atlantic gyre dynamics in glacial climate. Climate Dyn., 36, 1107-1118, doi:10.1007/s00382-009-0729-y.

Msadek, R., K. W. Dixon, T. L. Delworth, and W. Hurlin, 2010: Assessing the predictability of the Atlantic meridional overturning circulation and associated fingerprints. Geophys. Res. Lett., 37, L19608, doi:10.1029/2010GL044517.

_ , and Coauthors, 2014: Predicting a decadal shift in North Atlantic climate variability using the GFDL forecast system. $J$. Climate, 27, 6472-6496, doi:10.1175/JCLI-D-13-00476.1.

Read, J., 2000: Water masses and circulation of the northeast Atlantic subpolar gyre. Prog. Oceanogr., 48, 461-510, doi:10.1016/ S0079-6611(01)00011-8

Rhein, M., and Coauthors, 2011: Deep water formation, the subpolar gyre, and the meridional overturning circulation in the subpolar North Atlantic. Deep-Sea Res. II, 58, 1819-1832, doi:10.1016/j.dsr2.2010.10.061.

Robson, J., R. Sutton, K. Lohmann, D. Smith, and M. D. Palmer, 2012: Causes of the rapid warming of the North Atlantic Ocean in the mid-1990s. J. Climate, 25, 4116-4134, doi:10.1175/JCLI-D-11-00443.1.

Sévellec, F., and A. V. Fedorov, 2013: The leading, interdecadal eigenmode of the Atlantic meridional overturning circulation in a realistic ocean model. J. Climate, 26, 2160-2183, doi:10.1175/JCLI-D-11-00023.1.

Sidorenko, D., S. Danilov, and J. Schröter, 2008: Inverse solution for pentadal variability in the North Atlantic. Geophys. Res. Lett., 35, L02603, doi:10.1029/2007GL032463.

Spall, M. A., 2004: Boundary currents and watermass transformation in marginal seas. J. Phys. Oceanogr., 34, 1197-1213, doi:10.1175/1520-0485(2004)034<1197:BCAWTI>2.0.CO;2. 2012: Influences of precipitation on water mass transformation and deep convection. J. Phys. Oceanogr., 42, 16841700, doi:10.1175/JPO-D-11-0230.1. 
and D. C. Chapman, 1998: On the efficiency of baroclinic eddy heat transport across narrow fronts. J. Phys. Oceanogr., 28, 22752287, doi:10.1175/1520-0485(1998)028<2275:OTEOBE >2.0.CO;2.

Straneo, F., 2006a: Heat and freshwater transport through the central Labrador Sea. J. Phys. Oceanogr., 36, 606-628, doi:10.1175/JPO2875.1.

- 2006b: On the connection between dense water formation, overturning, and poleward heat transport in a convective basin. J. Phys. Oceanogr., 36, 1822-1840, doi:10.1175/JPO2932.1.

Thornalley, D. J. R., H. Elderfield, and I. N. McCave, 2009: Holocene oscillations in temperature and salinity of the surface North Atlantic. Nature, 457, 711-714, doi:10.1038/nature07717.

Uppala, S. M., and Coauthors, 2005: The ERA-40 re-analysis. Quart. J. Roy. Meteor. Soc., 131, 2961-3012, doi:10.1256/qj.04.176.

Våge, K., and Coauthors, 2009: Surprising return of deep convection to the subpolar North Atlantic Ocean in winter 20072008. Nat. Geosci., 2, 67-72, doi:10.1038/ngeo382.

van Aken, H. M., and C. J. de Boer, 1995: On the synoptic hydrography of intermediate and deep water masses in the Iceland Basin. Deep-Sea Res. I, 42, 165-189, doi:10.1016/0967-0637(94)00042-Q.

Visbeck, M., J. Marshall, and H. Jones, 1996: Dynamics of isolated convective regions in the ocean. J. Phys. Oceanogr., 26, 1721-1734, doi:10.1175/1520-0485(1996)026<1721:DOICRI > 2.0.CO;2.

Wouters, B., W. Hazeleger, S. Drijfhout, G. J. Van Oldenborgh, and V. Guemas, 2013: Multiyear predictability of the North
Atlantic subpolar gyre. Geophys. Res. Lett., 40, 3080-3084, doi:10.1002/grl.50585.

Xu, X., H. E. Hurlburt, W. J. Schmitz, R. Zantopp, J. Fischer, and P. J. Hogan, 2013: On the currents and transports connected with the Atlantic meridional overturning circulation in the subpolar North Atlantic. J. Geophys. Res. Oceans, 118, 502516, doi:10.1002/jgrc. 20065 .

Yashayaev, I., 2007: Hydrographic changes in the Labrador Sea, 1960-2005. Prog. Oceanogr., 73, 242-276, doi:10.1016/ j.pocean.2007.04.015.

Yeager, S., and G. Danabasoglu, 2014: The origins of late twentiethcentury variations in the large-scale North Atlantic circulation. J. Climate, 27, 3222-3247, doi:10.1175/JCLI-D-13-00125.1.

- A. Karspeck, G. Danabasoglu, J. Tribbia, and H. Teng, 2012: A decadal prediction case study: Late twentieth-century North Atlantic Ocean heat content. J. Climate, 25, 51735189, doi:10.1175/JCLI-D-11-00595.1.

Yoshimori, M., C. C. Raible, T. F. Stocker, and M. Renold, 2010: Simulated decadal oscillations of the Atlantic meridional overturning circulation in a cold climate state. Climate Dyn., 34, 101-121, doi:10.1007/s00382-009-0540-9.

Zhang, S., M. J. Harrison, A. Rosati, and A. Wittenberg, 2007: System design and evaluation of coupled ensemble data assimilation for global oceanic climate studies. Mon. Wea. Rev. 135, 3541-3564, doi:10.1175/MWR3466.1. 